\title{
The cyclic model of use diffusion-adoption on the decision to select mobile network operator
}

\author{
Widya Granita $^{a^{*}}$, Ngadino Surip ${ }^{a}$, Yuli Harwani ${ }^{a}$ and Rina Astini ${ }^{a}$
}

${ }^{a}$ Mercu Buana University Jakarta, Indonesia

\begin{tabular}{l}
\hline C H R O N I C L E \\
\hline Article history: \\
Received: June 20, 2020 \\
Received in revised format: \\
August 302020 \\
Accepted: September 18, 2020 \\
Available online: \\
September 18, 2020 \\
\hline Keywords: \\
Cyclic \\
Task Technology Fit \\
Needs Technology Fit \\
Usage Behavior \\
User Evaluation
\end{tabular}

\section{Introduction}

The rapid development of technological innovations in cellular services in recent years has increased the potential for retaining existing users and attracting new customers as a significant source of revenue for mobile network operators (MNO), device manufacturers, content providers and application developers (Fuentelsaz et al., 2008). Cellular services are produced by content and application developers or the mobile operators themselves. Cellular services are classified into the categories of communication, entertainment, information, transactional, and Web2.0 (Bouwman, Bejar, \& Nikou, 2012; Kuo \& Chen, 2006; Nysveen \& Pedersen, 2005; Varshney 2005). Although some services and applications have been very successful in the cellular market, there are several important things to achieve user satisfaction, including service quality, service standardization, content quality, and service conformity to needs and demands. Cellular technology continues to develop rapidly, cellular network deployed 4G/Long Term Evolution (LTE) technology, which has data speeds of up to 100 Mbps. The next network technology which is being prepared for commercialization shortly is $5 \mathrm{G}$ technology. The $5 \mathrm{G}$ access network is expected to support data transmission speeds of up to 1 Gigabyte per second (Gbps) (Next Generation Mobile Network Alliance, 2016). Improved performance and developments in wireless technology are advancing and driving an exponential increase in cellular network traffic. The cellular network consists of various physical components required for communication services performed by users. It is undeniable that digital technology has changed the telecommunication business map, especially cellular services (Evans et al., 2006; Tiwana et al., 2010; Zammuto et al., 2007), where digital services can be recombined quickly and easily into a new form.

\footnotetext{
* Corresponding author.

E-mail address: granitawidya@gmail.com (W. Granita)

(C) 2021 by the authors; licensee Growing Science, Canada doi: $10.5267 /$ j.msl.2020.9.029
} 
The convergence of mobile services is increasingly attractive and varied, for example, online transaction services also have communication, information, and entertainment features. The results of the study by Nikou and Mezei (2013) show that many substantial factors play an important role in deciding to choose a cellular service. These factors can be classified as (1) payment method and usage method, (2) cellular service function on the device, (3) the added value of using cellular services that can improve user performance, (4) perceived quality, cost, and performance. This provides a positive utility that influences usage behavior, especially in deciding to choose MNO. In the size of the Indonesian telecommunications market, economic dynamics will balance innovation, then achieve market stability and distribute market share between innovations (Kamel \& Watfa, 2018). MNO provides the best service to users by offering the best heterogeneous mobile network. Cellular devices can access cellular services using network technology provided by MNO (Reji Kumar \& Sudharani Ravindran, 2012) so that the use of cellular phones become more numerous and varied. MNO provides a network platform to access various online services. Cellular services are very important across all age groups, lifestyles, and motivations to use services (Ahmad, 2012). Young people adopt mobile service innovations such as multimedia messaging services (chat applications), streaming music, web searches, cameras, videos, mobile money, GPS, and others. On the other hand, MNO must innovate supported by investments in technology and cellular network infrastructure to increase the availability and quality of data services with higher access speeds (Ghezzi et al., 2015).

Mobile services have characteristics that provide different values to their users (Balasubramanian et al., 2002). When compared to other, cellular services are considered homogeneous because they have certain regulatory standards (Lim et al., 2006). One of them, cellular services can become a new marketing channel so that the use of cellular technology continues to increase from time to time. Cellular services continue to grow and provide hedonic value to technology, accompanied by the growth of various applications and high penetration rates of wireless devices (Kleijnen et al., 2007; Wang \& Lin, 2012). Data services, in general, are the use of the internet through sophisticated cellular devices, namely smartphones (Srinuan et al., 2013). The use of mobile data services, which is growing rapidly, has become a revenue stream for cellular operators, as well as a solution to increase revenue from voice and messaging services, which tends to decline. Data services have now become one of the most promising and profitable market segments worldwide. Understanding the behavior of data service users after purchase is essential to ensure the sustainable profitability of a mobile operator's business. The challenge faced by MNO is not only the rapid development of technology but also facing the dynamically changing telco market. MNO must utilize all resources to continue to innovate to create sustainable top-line revenue (Wang et al., 2016).

Several previous studies on cellular services and applications show the adoption process of cellular services (Chong et al., 2012; Smura et al., 2009), mobile game services (Liang \& Yeh, 2011), communication, and information services (Siau \& Shen 2003). This previous research aims to identify the determinant factors for the successful adoption of cellular services based on the perspective of user needs or from the side of the cellular operator itself. According to Feijóo et al. (2009) and (Shao, 2009), user characteristics and consumer perceptions about data services from operators are the main things. Therefore, consumers' decisions in choosing cellular operators are based on the perspective of matching their needs with cellular technology and cellular service functionality as important factors in actual usage behavior and user evaluation. Both will be the basis for the user's decision to keep choosing the same operator. Usage behavior and user evaluation are needed to identify the factors that influence the adoption of the type of cellular service that end-users like the most.

This study aims to form a cyclic model in the decision to choose MNO with usage behavior and user evaluation to increase actual usage and satisfaction with cellular services. Thus, users will remain customers of the operators they have chosen even though new technology is implemented. The cyclic model was designed using NTF and TFF as the basis for decisions to choose MNOs that shape usage and user evaluation behavior. Thus, this model can be used to understand the main reasons for the decision to choose MNO, which can shape positive usage and user evaluation behavior, which can lead to customer loyalty and increased usage. Thus, MNO's revenue will also increase.

\section{Theoretical Framework and Hypotheses}

\subsection{User's Decision Behavior on Cellular Data Services}

According to (Antonopoulos et al., 2017), the combined effect of increased diffusion of smartphones and digital services that become more accessible through data service packages tends to change the needs of end-users. Cellular users have replaced conventional communication platforms or legacy services, so-called voice and SMS, switching to data services. The behavior always-on to always-best connected of technology network connection based on the needs that fit from the function of cellular services (Gustafsson \& Jonsson, 2003). According to Partala and Saari (2015), similar variables have been applied to the study of interactive systems in the field of user experience research (UX), which is currently one of the most significant factors in human-technology interaction research. While there is a large body of literature on technology-choosing decisions and a growing number of studies on user experience, few studies have combined the two. The success of the information system model from various studies (Bharati \& Chaudhury, 2006; DeLone \& McLean, 1992; Seddon \& Freeman, 2004; Davis, 2013) emphasize the importance of system quality and information quality in improving system use, user satisfaction, culminating 
in increased personal and organizational performance. Here we describe the interplay between decision to choose mobile network operator and usage behavior and user evaluation. Fig 1 shows the research framework.

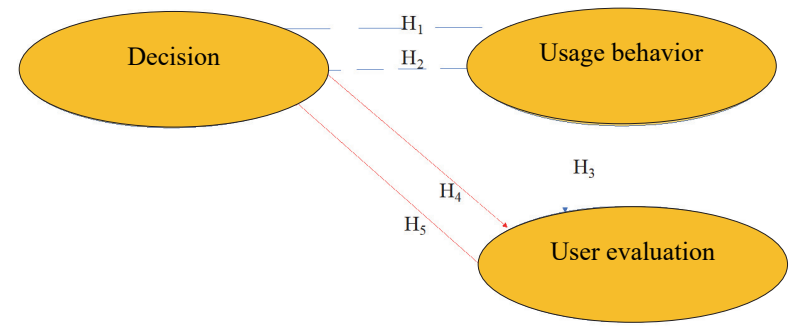

Fig. 1. The proposed model

\subsection{Decision}

The TTF model, introduced by Goodhue and Thompson (1995), is a model of the fit of technology with user tasks, where existing technology is utilized to support the completion of user tasks. In more depth, TTF explores the compatibility between technology, task, and user. If technology supports the need for better task completion, it improves performance. The users will make this the basis for using technology with the service of the cellular operator they choose. The measure of task technology fit developed by Goodhue and Thompson (1995), consists of eight factors: quality, capability, authorization, compatibility, ease of use, timeliness of production, system reliability, and user relationships. Through the measurement of TTF, it found that the relationship between technology services and usage is a significant predictor of increased performance and job effectiveness with the use of the system. Since its inception, TTF has applied in the context of various information systems such as electronic trading systems. TTF has been used as an extension of other models related to information technology outcomes such as the Technology Acceptance Model (TAM). The measurements presented on the TTF have undergone many modifications according to the specific study objectives. Information technology encourages active use only if it has features that meet the user's task needs functionally (Klopping \& Mckinney, 2004; Lin, 2016; Lu \& Yang, 2014; Yen et al., 2010a). From a user's cognitive perspective, the suitability between task characteristics and technology is the main factor that directly influences the intention to use information technology that will improve performance. It shows that the level of suitability between tasks, technology, and users affects performance, in turn, affects the behavior of using technology.

In the past, TTF was widely used to explore the performance of information systems in companies by observing the characteristics of employees' tasks and existing systems. Therefore, the TTF framework has not been applied to other fields or explored them individually. However, taking into account users as individuals, some researchers (Klopping \& Mckinney, 2004; Lin, 2016) adopt TTF as a theoretical basis for exploring usage behavior in other fields. Using TTF, Yen et al. (2010a) examined the factors that influence the reception of wireless technology, for example, cellular operators. The results show that the level of suitability between tasks and technology has a significant effect on the use of cellular operator networks. Kotler and Keller (2016) explain that purchasing decisions are in the form of an evaluation stage where consumers build preferences between brands in a set of choices. In carrying out the purchase intention, consumers make sub decisions: choice of brand, product, distributor, purchase quantity, purchase time, and payment method. It is in line with the statement (Goodhue \& Thompson, 1995) that the TTF component consists of dimensions: data quality, capability, data access authorization; data compatibility, training and ease of use, timelines, system compatibility, and technology relationships with users. This study uses the TTF model as the basis for decisions in choosing cellular operators. The dimensions of the decision to choose the operator were using Goodhue's TTF theory and Kottler's purchase decision, namely:

Some researchers, (e.g. Kwai Fun IP \& Wagner, 2008; Lin, 2012; Yen et al., 2010) stated that the TTF theory is necessary to explain consumer behavior when using information technology services. Kwai Fun IP and Wagner (2008) stated the needs is a determining factor that affects the use of technology services to complete tasks. The user needs represent the task so that the needs for technology fit (NTF) is stated as a dimension of decision making using the TTF model (Lin, 2016). In line with the above, the perceived technology fit needs represent a synthesis of sub-purchasing decisions (Kotler \& Keller, 2016), namely the selection of brands and products of mobile network operators (MNOs), distributors, and payment methods. With the embodiment of TTF dimensions (Goodhue \& Thompson, 1995), namely: data quality, location, authorization, data systems, training and ease of use, and time. In decision making, TTF developed to understand users in selecting and evaluating cellular services, where individual needs are fit technological suitability (Dishaw \& Strong, 1998). This study uses a model of TTF as a basis for the decision in choosing an MNO. The second dimension of the decision to choose a cellular operator in this study is technology functionality fit (TFF). It based on the suitability of the user requirements with network functionalities accessed through a device (Negahban \& Chung, 2014). User characteristics also affect TFF, so the adoption of technology services is a product of task and technology characteristics that affect user performance and actual usage (Zhou et al., 2010). The concept of fit in the context of cellular technology by Gebauer et al. (2005) identified five factors that are appropriate for cellular services, namely: voice communication; mobile office; support for knowledge; productivity, and versatility; 
as well as wireless features and network stability. The dimensions of technology functionality fit are in line with the thought of purchasing decisions (Kotler \& Keller, 2016), namely the choice of product and time and quantity of use, and consistent with the TTF Goodhue components: system reliability (reliable system) and relationship with users (the interaction between cellular operators and users). The unique nature of cellular services that it accessed from anywhere and anytime via a device. The rapid advancement of device technology creates a multi-function on a cellphone to access cellular networks (Negahban \& Chung, 2014). Therefore, MNOs must continue to provide access to a network technology that is interoperable with all types of devices. A device is an interface to connect to a cellular network. The device characteristics and network capabilities are an important factor in using cellular services (Sarker \& Wells, 2003). On the other hand, cellular operators have also prepared customer service that can be accessed from various digital platforms, so that connection with users is never interrupted.

\subsection{Usage Behavior}

Use Diffusion Model (UDM) is an alternative approach from the adoption of innovation to the use of the innovations. Shih and Venkatesh (2004) stated that UDM can explain and predict the diffusion of technology. UDM explores consumer usage patterns at the post-adoption stage and to determine the usage of subsequent innovations. UDM can take into account various diffusion characteristics such as dimensions of technology use, levels of usage, and different usage variations to determine how the innovation will work in the market in the long run. Thus UDM can be widely applied as an explanation for the further diffusion of a product or service that has technical complexity, such as the convergence of digital products that offer various functions (Kim et al., 2007). The Diffusion Use Model links consumer decision making and usage behavior. The proposed typologies of use are intense use, specialized use, non-specific use, and limited use. The UD model is divided into general constructs, namely innovation, social communication, complexity, media influence, and relative benefit. However, this arrangement may not be the same in content. For example, innovation adoption is not the same as innovation users (Ridgeway $\&$ Price, 1994). Meanwhile, the uniqueness of the diffusion adoption (AD) model is a relative advantage, compatibility, and trialability (Rogers, 2003), while the UD model includes experiences in using technology that is positive or negative in use, technological sophistication, and user satisfaction. Consumers have the motivation and desire when making a purchase, imagine the product or service according to their wishes. Meanwhile, in post-use, consumers will feel the value of the product or service. The concept of the Use-Diffusion (UD) model (Shih \& Venkatesh, 2004). This model has three main components: (1) determinants of UD, (2) patterns of UD, and (3) results of UD. Each of these components has several sub-components. Although the three are inseparable from the model, the UD pattern (i.e. usage typology of user typology) plays an important role in the diffusion of use. The use of a product or service influences actions, experiences, emotions, feelings, attitudes, and even influences the next phase of consumer behavior (Schiffman \& Wisenblit, 2015). Of course, the consumer's decision to use a product or service before experiencing and gaining experience from the service. At the first time of use, it will form a user evaluation that determines the user's attitude towards the product or service. Usage behavior consists of use intensity and uses variety, analogous to the depth of use, and the breadth of use in the innovation diffusion literature (Robertson \& Gatignon, 2012). The intensity of use so-called depth of use explains the number of usage or the number of purchases of a product or service. This definition is macro usage in the context of diffusion of innovation, but this research focuses on the use of cellular services at the individual (micro) level. The conceptualization of use consists of two distinct dimensions: use variety and use intensity. Usage pattern refers to the different ways and how many times a product or service is used. Usage intensity refers to the high usage of a product or service during a specified period. Although the intensity and variety of use are correlated, namely the high the variety is, the higher the level of use, the relationship between the two is not empirically tested (Sawng et al., 2013). Sustainable use demonstrates the potential for technology development cycles by measuring the use of technology services and also exploring mobile applications that benefit end-users, content, and application developers, as well as retailers and dealers. Mobile operators must maintain customer satisfaction through the use of useful networks and services to get a large and loyal customer base (Shaw et al., 2018). One of the decisions to choose a cellular operator is the need for motivation. If cellular services can meet user needs obtained from technology functions, users will continue to consume services because they feel satisfied with cellular technology. Chang et al. (2013) stated that in terms of needs motivation, usage behavior revealed that utilitarian motivational needs (perceived benefits) had a higher direct effect on continuous use intentions than hedonic motivational (perceived playfulness). The intent to use technology affects the user's purposes.

\subsection{User Evaluation}

Research on consumer behavior is mostly on product evaluation considerations that lead to a goal. Consumers usually perform evaluations for specific purposes of use. Evaluative criteria consist of a series of product or service characteristics that are relevant and describe the features and performance levels of the product that consumers want (Gardial et al., 1994). Consumers will attempt to assess the performance of a product or service according to these criteria before purchase and compare it to actual performance after use. Also, evaluative criteria can change when consumers find out which product features are not as expected before purchasing. In the end, a different criterion needs to choose between product alternatives and actual product performance evaluation ( $\mathrm{Ju}, 2011)$. Therefore, one of the reasons operators need to analyze user evaluations is useful for increasing customer retention. It obtains from the perception of service quality, perceived value, variation, and intensity of use, user satisfaction, and interest in the next generation of cellular technology. Research by Chakraborty and Sengupta (2014) regarding the main factors of consumer satisfaction with mobile operators in India, resulted in findings that mobile operators 
need to identify the level of user satisfaction because it can affect service adoption and use. It is in line with the cost of acquiring new users is higher than the cost of serving existing customers. Satisfaction is a post-purchase evaluation in the form of affective response to the overall experience of using a product or service (Oliver, 1980). Satisfaction is also a response to the fulfillment of needs obtained from the use of services (Oliver et al., 1997). Customer satisfaction also plays an important role in the sustainability of a brand's existence, especially for cellular operators. Users will gain knowledge and skills regarding the operationalization of cellular technology services lead to their interest in new technology. For the long-term relationship between cellular operators and their customers (subscribers) to be maintained, customer satisfaction is a determinant factor. The results of the study by Chakraborty and Sengupta (2014) show that MNO that offer services, namely quality networks, the ability to connect to others, and reasonable prices, can satisfy consumer needs.

In developing products or services based on next-generation technology, MNO must ensure the factors that can attract and make consumers become loyal customers. Additionally, mobile operators need to identify the extent to which interest in the latest technology influences the acceptance of a revolutionary new product or service at a significantly higher price than previous generations. $\mathrm{Ju}$ (2011) in a study on the increasing adoption of mobile operator services in China, found that user knowledge comes from experience to understand new technologies and how to apply skills to use them, giving rise to knowledge of these technologies as well as interest in new technologies. For data service users, the balance between cognitive and affective aspects affects the attitude of product purchase decisions (Shih \& Venkatesh, 2004). Previous experiences will help users better understand and make it easier to use new technology services. Interest in new technology arises because high-tech services and products provide a variety of functions with convenient services so that innovative users tend to switch to using new products or services by comparing other products or services that are previously or existing. Shin and Jin Park (2017) conducted a study measuring the quality of experience using new 5G/Internet of Things (IoT) technology in Korea. The interesting findings that quality of technology has a positive effect on IoT. The convenience of the technology system influences the user to enjoy mobile services: the more power the system, the higher the level of enjoyment. Thus, it is possible for users who are interested in new technology to continue to choose the same MNO when the latest technology is implemented in their cellular network. The socio-technical perspective requires that the design and development of new technologies based on individual needs and that ultimately a system must be human-centered (Yoo et al., 2010). This argument is consistent with the normalization perspective that technology design and analysis on a contextual understanding, namely, evaluation based on the latest technology (Shin \& Jin Park, 2017). Thus, consumers will choose the technology that best fits their needs. For instance, in selecting an MNO, differences in individual behavior can predict the use of services with certain features (Shaw et al., 2018).

\subsection{Interplay of decision to choose an MNO on Usage Behavior}

In research by Goodhue and Thompson (1995) Task Technology Fit is used to assist in making decisions about choosing IT services. (Liu et al., 2011) interpret the concept of "fit" as an indication of the suitability and unity of perspective between individual motivation needs and purchasing decisions. The fit operational approach is a match between task and technology, and the fit of technology service functions used. Several researchers, namely (Lin 2012; Kwai Fun \& Wagner 2008; Yen et al. 2010b) state that the TTF theory is necessary to explain consumer behavior when using information technology services. (Kwai Fun IP \& Wagner, 2008) stated that need is a determining factor that influences the use of technology services to complete tasks so that in his research, user motivational needs represent tasks so that the need for technology fit is stated as a dimension of decision making using the TTF model. The use of cellular services occurs because it is following the needs, goals, or objectives of each individual, but distinct ways of achieving the results, accompanied by the influence of the environment or individual context, can shape differences in usage behavior (Ram \& Jung, 1990). When these differences in behavior occur, cellular operators will provide flexibility to users to try various service alternatives that raise preferences and assess the perceived benefits of users (Ju, 2011).The individual behavior is different from one another, as well as the stages of the experience of use, and the perceived value will also be different. The characteristics of user behavior can influence the decision to choose a cellular operator because it can provide solutions to meet consumer needs (Negahban \& Chung, 2014). Therefore, the application of cellular technology is a product of the characteristics of needs and technology (NTF) that affect user performance in actual use (Zhou et al., 2010). It implies that the high compatibility of needs and technology will encourage user adoption of technology. Meanwhile, low suitability of needs and technology will harm users' intention to adopt technology with an increase in the intensity and variety of use (Lee et al., 2007; Zhou, 2014). Thus, the following hypothesis postulated:

\section{H1. The decision to choose a cellular operator has a positive and significant effect on user behavior. $\mathrm{H} 2$. Usage behavior has a positive and significant effect on the decision to choose an MNO.}

\subsection{The interplay of decision to choose an MNO on User Evaluation}

The results of the study $(\mathrm{Ju}, 2011)$ indicate that the need for awareness and influence of technology obtained by comparing the current and past user behavior; compare goals or objectives with mobile service functionality, or compare between expectations and results. The more often you use technology functionality, it will directly shape the perception of technology that affects everyday life. On the one hand, the use of high technology and the use of technological diversity have become an integral part of the user and control the operationalization of the user's daily activities. On the other hand, intensity the use of 
technology and its diversity does not affect the perception of the effect of technology, if the use frequency and use a variety were not completed. The customer's journey on mobile services begins when the consumer decides to become a subscriber to the MNO they choose. Then the user accesses the network, gets cellular service, and uses and enjoys the type of service they want. A satisfying experience will increase the intensity of use by increasing the consumption of these types of services (repeated use). It is also called usage renewal or continuous usage. The decision to choose a mobile operator and user evaluation influence one another. The finding $(\mathrm{Ju}, 2011)$ is the occurrence of repeated use of mobile services by adopting the broadband diffusion model but ignoring the adoption-diffusion (AD) phase. Repeated use occurs after a mobile operator gets feedback on the user's experience using cellular services in terms of changes in usage patterns. It is emphasized by (Olson et al., 2011; Shih \& Venkatesh, 2004) that the function of technology is a determinant factor that influences usage behavior patterns. In this case, usage will continue when MNO modernize the network through new technologies. Research (Shih \& Venkatesh, 2004) has proven empirically that the intensity of use plays a role in repeated use, which the factor of interest in using new technology. It is based on user experience to form the perception of the importance of high-tech cellular services to improve user skills and abilities as well as knowledge. Based on the description above, a hypothesis built:

H3. Usage behavior has a positive and significant effect on user evaluation.

H4. The decision to choose MNO has a positive and significant effect on user evaluation.

H5. Usage evaluation has a positive and significant effect on the decision to choose an MNO.

\section{Research methods}

This study conducted to unify the adoption-diffusion process of cellular services is the basis for the decision to choose an operator with a use-diffusion process that shapes usage behavior and user evaluation to determine its effect on repeated use of services from the selected operator. This research conducted referred to previous research (K. Y. Lin, 2016; Negahban \& Chung, 2014; Shih \& Venkatesh, 2004). There are three variables studied with two dimensions each. Some indicators are used to measure the decision to choose MNO, usage behavior, and user evaluation. For decision variables (NTF and TFF) we uses six indicators taken from the theory (Goodhue \& Thompson, 1995). As for usage behavior (use intensity and use variety) we use four indicators adapted taken from previous study ((Ram \& Jung, 1990; Shih \& Venkatesh, 2004), and for user evaluation (satisfaction and interest to technology) we use six indicator obtained from ((Ju, 2011; Sawng et al., 2013). Besides, all statements items measured by the Likert scale, ranging from 1 to $5,1=$ strongly disagree, and $5=$ strongly agree. The analysis method used in this research is the Structural Equation Model (SEM) with LISREL 8.7. In this study, the population used is prepaid and postpaid cellular card users from licensed MNO, namely Telkomsel, XL-Axiata, Indosat-Ooredo, and 3Hutchinson and Smartfren in the DKI Jakarta area. The data in this study came from a sample that represents the behavior of the population. Jakarta chooses as the location for sampling by considering that all forms of new services, as well as available services, require cellular infrastructure support is always available in Jakarta. The number of respondents was 250 people with the reference that the required sample is five times the number of variables (Ferdinand, 2002). Sampling in this study conducted using a non-probability sampling method with a purposive sampling technique. According to (Malhotra, 2010) nonprobability sampling is a sampling technique that does not use opportunity selection procedures but relies on the personal judgment of the researcher. The majority of respondents were female (54.26\%), 16-25 years of age in the year against the background of the students (78.68\%), income $>1-2$ million rupiahs/month. Most respondents choose MNO Telkomsel (53.01\%). Most consist of prepaid card users (27.82\%) and postpaid (25.19\%). Overall, the mobile operator at least selected respondents are Smartfren (2.63\%), followed by 3-Hutch (9.02\%), XL Axiata (20.30\%), and Indosat-Ooredo (15.04\%). The postpaid user contributes as much as $46.9 \%$, and the prepaid card is $46.51 \%$. Length of Stay ( LOS) or duration of MNO have been selected by the respondents who had used the Subscriber Identification Module (SIMcard) for more than six months amounted to $93.8 \%$. It suggests that the relative SIMcard users continue to use their cards rather than change it to another MNO.

Table 1

Result of Validity and Reliability Test

\begin{tabular}{|c|c|c|c|c|c|}
\hline Indicator & SLF & Errors & T-Value & $\mathrm{CR}$ & VE \\
\hline DMNO1 & 0.79 & 0.35 & 11.37 & \multirow{6}{*}{0.9663} & \multirow{6}{*}{0.6424} \\
\hline DMNO2 & 0.82 & 0.25 & 7.60 & & \\
\hline DMNO3 & 0.81 & 0.24 & 11.97 & & \\
\hline DMNO4 & 0.78 & 0.39 & 12.11 & & \\
\hline DMNO5 & 0.73 & 0.37 & 11.69 & & \\
\hline DMNO6 & 0.77 & 0.35 & 11.51 & & \\
\hline UB1 & 0.72 & 0.38 & 8.06 & \multirow{4}{*}{0.8721} & \multirow{4}{*}{0.6383} \\
\hline UB2 & 0.74 & 0.36 & 9.67 & & \\
\hline UB3 & 0.71 & 0.39 & 7.78 & & \\
\hline UB4 & 0.68 & 0.40 & 6.02 & & \\
\hline UE1 & 0.75 & 0.34 & 15.93 & \multirow{6}{*}{0.8195} & \multirow{6}{*}{0.6028} \\
\hline UE2 & 0.83 & 0.22 & 9.49 & & \\
\hline UE3 & 0.85 & 0.28 & 9.49 & & \\
\hline UE4 & 0.80 & 0.25 & 12.16 & & \\
\hline UE5 & 0.72 & 0.32 & 10.05 & & \\
\hline UE6 & 0.76 & 0.36 & 10.29 & & \\
\hline
\end{tabular}

**) SFL $=$ Standardized Factor Loading, Good SLF value

***) $\mathrm{VE}=$ Vonsturce Reliabiliny, Good CR value $>-0.70$ 
A validity test uses Confirmatory Factor Analysis. Refer to the loading factor of each indicator and the AVE (Average Variance Extracted) of each construct as a measure of convergent validity. The validity and reliability of the test results are shown in Table 1 . The Construct Reliability (CR) are $0.9663 ; 0.8721 ; 0.8195 \geq 0.70$. Total score variance Extracted (VE) are 0.6424 ; $0.6383 ; 0.6028 \geq 0.50$. The results show all the indicators of the decision to choose MNO (DMNO); Usage Bevahior (UB); and User evaluation (UE) can explain the technology mobile and device functions suitable to form usage behavior and user evaluation of mobile service usage. Before making hypotheses, all models (the overall fit model), first valued to ensure that the model can illustrate all ties and effects (goodness of fit). The full model built in this research started as a good, hypothesis test will be continued. Model test result with various measurements goodness-of-fit are given in Table 2 and Fig. 2 . Having obtained the overall model fit was good, followed by a test of hypothesis to answer the problem formulation in this study. Hypothesis test results are presented in Table 2, and the structural model analysis have shown in Fig. 2: Standardized Loading Factor and Result of t-test ( $\mathrm{t}$-value inside the bracket).

Table 2

Test Results Overall Model Fit

\begin{tabular}{lccc}
\multicolumn{1}{c}{ Goodness-of-Fit } & Cut-off- & Result & Judgment \\
\hline Degree of Freedom (DF) & Positive & 45 & Good \\
Chi-Square ( $\chi^{2}$ ) & Small num- & 64.09 & Good \\
P-Value & $\geq 0.05$ & 0.05138 & Good \\
$\begin{array}{l}\text { RMSEA (Root Mean Square Error of Approxima- } \\
\text { tion) }\end{array}$ & $\leq 0.08$ & 0,033 & Good \\
GFI (Goodness of Fit) & $\geq 0.90$ & 0,96 & Fit \\
AGFI (Adjusted Goodness of Fit Index) & $\geq 0.90$ & 0,94 & Good \\
CFI (Comparative Fit Index) & $\geq 0.90$ & 0,99 & Good \\
\hline
\end{tabular}

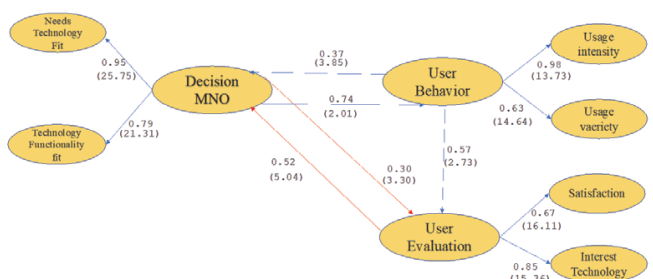

Chi-Square $=64.09 \mathrm{df}=45$ P-value $=0.0513189$ RMSEA $=0.033$

Fig. 2. Standardized loading factor and results of t-test ( $\mathrm{t}$-value, inside the bracket)

Table 3 shows the path coefficient and t-test to explain the interplay between usage behavior on the fit of the use of technology; user evaluation on the fit of technology. The results of hypothesis testing can explain that all the hypotheses are positively built based on facts obtained (path coefficient $0.74 ; 0.30 ; 0.57 ; 0.37 ; 0.52$ ) and t-test values $2.01 ; 3.30 ; 2.73 ; 3.85$ and 5.04 . The results have shown positive and significant influence the decision to choose an MNO on usage behavior and usage evaluation, and vice versa. In addition, it was found that usage behavior had a positive and significant effect on user evaluation. The stronger the decision to choose MNO, the stronger it is to form usage behavior and vice versa. The stronger the decision to choose $\mathrm{MNO}$, the more positive the user evaluation is. In addition, the results of this analysis also show that the more the usage behavior is formed, the more positive the user evaluation is.

Table 3

Results of Hypotheses Testing

\begin{tabular}{lllll}
\hline & Hypotheses & SLF & T-value & Result \\
\hline H1: DMNO & $\rightarrow$ UB & 0.74 & 2.01 & Supported \\
H2: UB & $\rightarrow$ DMNO & 0.37 & 3.85 & Supported \\
H3: UB & $\rightarrow$ UE & 0.57 & 2.73 & Supported \\
H4: DMNO & $\rightarrow$ UE & 0.30 & 3.30 & Supported \\
H5: UE & $\rightarrow$ DMNO & 0.52 & 5.04 & Supported \\
\hline
\end{tabular}

Source: The Result of Data Procesing Lisrel 8.7)

\section{Discussion and Conclusion}

The results have that the decision to select an MNO influenced usage behavior and user evaluation. On the other hand, usage behavior and user evaluation have a positive and significant effect on the decision to choose a cellular operator. The decision to choose MNO is a key factor in a sustainable use, marked by high use intensity and use variety. It implies that the increasing of a decision to choose an MNO will increase the intensity and variety of mobile service usage. In line with the research results (Ahmad, 2012), the factors that can meet the fit of technology will influence the usage behavior and repeated use. The flexibility of mobile technology allows users to personalize device functions based on their needs. Perceptions of technology in individuals can limit as well as fulfill the need to achieve goals. The user experience feels the capabilities and functionality of cellular technology and devices in meeting their needs, then the behavior of using cellular technology becomes a routine (Lin, 2016). The actual usage of data services has increased very sharply in the technological disruption era. The presence of OTT applications that offer voice and instant messaging as well as other digital services such as online shopping, online payments, etc., encourages a variety of uses, also increases the intensity of use and repeated use (Negahban, 2012). When a device is integrated into a routine, the user feels a higher level of the fit between the mobile service functionality and their needs. Individually, the intensity of use increases with the increasing variety of services used (Leonardi, 2011). It concluded, the stronger the decision to choose a cellular operator to provide usage behavior in the form of an increased variety of usage, the higher the intensity. Thus, the variety of cellular service usage increases accordingly. Delivered by Liu et al. (2011) a similar statement that the contextual factors of the situation and location are also very important in the actual adoption and 
use of technology. The fit of technology to needs and functionality has been predicted to increase user satisfaction. The satisfaction of technology has built on a positive belief in the characteristics or results of the function of a product or service that can meet consumer needs (Liu et al., 2011). An increasingly satisfying experience using cellular technology will give users the choice to use the system already owned by the operator they have chosen and generate a sense of interest and interest in the new cellular technology implemented by the operator. It is in line with the findings (Lin, 2016; Liu et al., 2011) that the functions and benefits of developing technology can be seen from the satisfaction of using technology and the interest in changing technology itself from time to time.

The findings of this study, the decision to choose the MNO became a turning point in mobile services usage behavior hereinafter with reference to the potential use of behavior become loyal customers. Also, the usage behavior states that experience determines the user's evaluation for making decisions chooses the same MNO. The experience of consumers in using cellular has both incomparable and intangible aspects, so the assumption is a mixed perception between products and services (Jin \& $\mathrm{Ji}, 2010$ ). According to Olson et al. (2011), in a dynamic mobile digital service environment (mobile digital services), user satisfaction is important to build long-term relationships with other users. Satisfaction with mobile digital services can use more usage and change intense usage patterns. Supported by Nikou et al. (2012) that the use of mobile services consists of voice communications services, SMS (Short Messaging Services), data services in the form of entertainment, information and transactions as well as applications and content increased the intensity of use and variety of use at a time. This comfort discourages users from switching carriers or MNO. Previous impressive usage experiences have reduced the level of risk of user dissatisfaction and even increased the benefits that will continue to be consumed (Shih \& Venkatesh, 2004). Intense users have the highest variety and usage levels, so they have a higher interest in new technology services such as $4 \mathrm{G}$ and $5 \mathrm{G}$. It is in line with the findings of Mehrad and Mohammadi (2017) that recommendations in word of mouth influence the decision to adopt cellular services from these operators. It is based on the compatibility of technology with the need for usability and pleasure. For the cellular telecommunications industry, the management of mobile service users is a strategy that can increase and maintain the number of users. Also, an increase the continuance use of cellular services may lead to an increase in operator revenue. Furthermore, the evaluation of users from the aspect of satisfaction with cellular technology services and interest in new technologies implemented by MNO suggests sustainable use. The research findings provide benefits: (1) Customer management that is designed based on user behavior so that it becomes a solution in meeting their needs, (2) Provides an impressive experience through the customer journey that provides a satisfaction value, (3) Provides customized services innovation according to their needs and customer desire (4) Offers a variety of cellular service packages in collaboration with device manufacturers and application development to meet the always-on to always best-connected lifestyle (5) Improve network quality through coverage and speed of access. Besides, the mobile industry players can adjust the market mechanism, one of them by always following the rapid technological advances of the time.

\section{Limitation of the Research}

Research is based solely on factors: the decision to choose the operator, usage behavior, evaluation of users, and demographic factor. Many other factors can investigate in more depth; telecommunication market players are not only consumers, but also involve the government, device manufacturers, application and content providers, and network infrastructure providers. Of course, it will complete if research carries out with these objects. Also, this study only focuses on the selection of an MNO. Further research expects to analyze the user's choice for applications and content as well as the type of device being their preference.

\section{References}

Ahmad, N. (2012). Utilitarian and hedonic values of mobile services: A preliminary analysis from the users' perspective. Business \& Accounting Review, 9, 69-83.

Antonopoulos, A., Kartsakli, E., Perillo, C., \& Verikoukis, C. (2017). Shedding light on the Internet: Stakeholders and network neutrality. IEEE Communications Magazine, 55(7), 216-223.

Balasubramanian, S., Peterson, R. A., \& Jarvenpaa, S. L. (2002). Exploring the implications of M-commerce for markets and marketing. Journal of the Academy of Marketing Science, 30(4), 348-361.

Bharati, P., \& Chaudhury, A. (2006). Product customization on the web: An empirical study of factors impacting choiceboard user satisfaction. Information Resources Management Journal, 19(2), 69-81.

Bouwman, H., Bejar, A., \& Nikou, S. (2012). Mobile services put in context: A Q-sort analysis. Telematics and Informatics, 29(1), 66-81.

Chakraborty, S., \& Sengupta, K. (2014). Structural equation modelling of determinants of customer satisfaction of mobile network providers: Case of Kolkata, India. IIMB Management Review, 26(4), 234-248.

Chang, C. C., Liang, C., Yan, C. F., \& Tseng, J. S. (2013). The impact of college students' intrinsic and extrinsic motivation on continuance intention to use English mobile learning systems. Asia-Pacific Education Researcher, 22(2), $181-192$.

Chong, A. Y. L., Chan, F. T. S., \& Ooi, K. B. (2012). Predicting consumer decisions to adopt mobile commerce: Cross country empirical examination between China and Malaysia. Decision Support Systems, 53(1), 34-43.

Davis, F. D. (2013). Information Technology Introduction. 13(3), 319-340.

DeLone, W. H., \& McLean, E. R. (1992). Information systems success: The quest for the dependent variable. Information 
System Research, 3(1), 60-97.

Dishaw, M. T., \& Strong, D. M. (1998). TTF and TAM models. 36, 9-21.

Evans, D. S., Hagiu, A., \& Schmalensee, R. (2006). Invisible Engines: How Software Platforms Drive Innovation and Transform Industries. MIT Press.

Feijóo, C., Maghiros, I., Abadie, F., \& Gómez-Barroso, J. L. (2009). Exploring a heterogeneous and fragmented digital ecosystem: Mobile content. Telematics and Informatics, 26(3), 282-292.

Ferdinand, A. (2002). Stuctural Equation Modelling dalam Penelitian Managemen: Aplikasi Model-model Rumit dalam Penelitian Thesis dan Disertasi. Semarang (ID), Badan Penerbit Universitas Diponegoro.

Fuentelsaz, L., Maícas, J. P., \& Polo, Y. (2008). The evolution of mobile communications in Europe: The transition from the second to the third generation. Telecommunications Policy, 32(6), 436-449.

Gardial, S. F., Clemons, D. S., Woodruff, R. B., Schumann, D. W., \& Burns, M. J. (1994). Comparing Consumers' Recall of Prepurchase and Postpurchase Product Evaluation Experiences. Journal of Consumer Research, 20(March 1994), 548560.

Gebauer, J., Shaw, M. J., Gribbins, M. L., Gebauer, J., Shaw, M. J., \& Gribbins, M. L. (2005). Towards a Specific Theory of Task - Technology Fit for Mobile Information Systems. Journal of Strategic Information System, 25(3), 1-52.

Ghezzi, A., Cortimiglia, M. N., \& Frank, A. G. (2015). Strategy and business model design in dynamic telecommunications industries: A study on Italian mobile network operators. Technological Forecasting and Social Change, 90(PA), $346-354$.

Goodhue, D. L., \& Thompson, R. L. (1995). Task-technology fit and individual performance. MIS Quarterly: Management Information Systems, 10(3), 278-288.

Gustafsson, E., \& Jonsson, A. (2003). Alaways Best Connected. IEEE Wireless Communication, Februari, 49-55.

Jin, B. S., \& Ji, Y. G. (2010). Usability risk level evaluation for physical user interface of mobile phone. Computers in Industry, 61(4), 350-363.

Ju, S. Y. (2011). Telecom upgraded services adoption model using the use - diffusion theory: The study of China's telecommunications Market. International Journal of Organizational Innovation, 4(2), 77-122.

Kamel, A., \& Watfa, M. K. (2018). Disruption-based innovations for incumbent technology businesses. International Journal of Innovation, Creativity and Change, 4(2), 20-50.

Kim, H., Chan, H. C., \& Gupta, S. (2007). Value-based Adoption of Mobile Internet : An empirical investigation. Decision Support Systems, 43, 111-126.

Kleijnen, M., de Ruyter, K., \& Wetzels, M. (2007). An assessment of value creation in mobile service delivery and the moderating role of time consciousness. Journal of Retailing, 83(1), 33-46.

Klopping, I. M., \& Mckinney, E. (2004). Extending the technology acceptance model and the task-technology fit model to consumer e-consumer. Information Technology, Learning, and Performance Journal, 22(1), 35-48.

Kotler, P., \& Keller, K.L. (2016). Marketing Management. $16^{\text {th }}$ Edition. New Jersey: Pearson.

Kuo, Y. F., \& Chen, P. C. (2006). Selection of mobile value-added services for system operators using fuzzy synthetic evaluation. Expert Systems with Applications, 30(4), 612-620.

Kwai Fun IP, R., \& Wagner, C. (2008). Weblogging: A study of social computing and its impact on organizations. Decision Support Systems, 45(2), 242-250.

Lee, M. K. O., Cheung, C. M. K., \& Chen, Z. (2007). Understanding User Acceptance of Multimedia Messaging Services : An Empirical Study. Wiley InterScience, 58(13), 2066-2077.

Liang, T. P., \& Yeh, Y. H. (2011). Effect of use contexts on the continuous use of mobile services: The case of mobile games. Personal and Ubiquitous Computing, 15(2), 187-196.

Lim, H., Widdows, R., \& Park, J. (2006). M-loyalty: Winning strategies for mobile carriers. Journal of Consumer Marketing, 23(4), 208-218.

Lin, K. Y. (2016). User communication behavior in mobile communication software. Online Information Review, 40(7), 1071-1089.

Lin, W. (2012). Perceived fit and satisfaction on web learning performance : IS continuance intention and task-technology fit perspectives. Journal of Human Computer Studies, 70(7), 498-507.

Liu, C. T., Guo, Y. M., \& Lee, C. H. (2011). The effects of relationship quality and switching barriers on customer loyalty. International Journal of Information Management, 31(1), 71-79.

Lu, H. P., \& Yang, Y. W. (2014). Toward an understanding of the behavioral intention to use a social networking site: An extension of task-technology fit to social-technology fit. Computers in Human Behavior, 34, 323-332.

Malhotra, N. K. (2010). Marketing research: An Applied Orientation. Sixth Edition. Pearson Education.

Negahban, A., \& Chung, C. (2014). Computers in human behavior discovering determinants of users perception of mobile device functionality fit. Computers in Human Behavior, 35, 75-84.

Nikou, S., \& Mezei, J. (2013). Evaluation of mobile services and substantial adoption factors with Analytic Hierarchy Process (AHP). Telecommunications Policy, 37(10), 915-929.

Nysveen, H., \& Pedersen, P. E. (2005). Explaining intention to use mobile chat services: moderating effects of gender. Journal of Consumer Marketing, 22(5), 247-256.

Oliver, K. M., Wilkenson, G. L., \& Bennett, L. T. (1997). Evaluating the quality of internet information sources. In $E D-$ Media/ED-Telecom.

Oliver, R. L. (1980). A Cognitive model of the antecedents and consequences of satisfaction decisions. Journal of Marketing Research, 17(4), 460. 
Olson, K. E., Brien, M. A. O., Rogers, W. A., \& Charness, N. (2011). Diffusion of technology: Frequency of use for younger and older adults. Ageing International, 36, 123-145.

Partala, T., \& Saari, T. (2015). Understanding the most influential user experiences in successful and unsuccessful technology adoptions. Computers in Human Behavior, 53, 381-395.

Ram, S., \& Jung, H.-S. (1990). The conceptualization and measurement of need. Journal of the Academy of Marketing Science, 18(1), 67-76.

Reji Kumar, G., \& Sudharani Ravindran, D. (2012). An empirical study on service quality perceptions and continuance intention in mobile banking context in India. Journal of Internet Banking and Commerce, 17(1).

Ridgeway, N. M., \& Price, L. L. (1994). Exploration in Product Usage: A Model of Use Innovativeness: ABSTRACT. Psychology \& Marketing., 11(1), 69-85.

Sarker, S., \& Wells, J. D. (2003). Understanding mobile handheld device use and adoption. COMMUNICATIONS OF THE $A C M, 46(12), 6-9$.

Sawng, Y.-W., Motohashi, K., \& Kim, G. (2013). Comparative analysis of innovative diffusion in the high-tech markets of Japan and South Korea : a use - diffusion model approach. Service Business. Springer., 7, 143-166.

Seddon, P. B., \& Freeman, P. (2004). The case for viewing business models as abstractions of strategy. Communications of the Association for Information Systems, 13(March).

Shao, G. (2009). Understanding the appeal of user-generated media: a uses and gratification perspective. Internet Research, $19(1), 7-25$.

Shaw, H., Ellis, D. A., \& Ziegler, F. V. (2018). The technology integration model (TIM). Predicting the continued use of technology. Computers in Human Behavior, 83, 204-214.

Shih, C., \& Venkatesh, A. (2004). Beyond Adoption: Development and Application of a Use-Diffusion Model. 68(January), 59-72.

Shin, D. H., \& Jin Park, Y. (2017). Understanding the Internet of Things ecosystem: multi-level analysis of users, society, and ecology. Digital Policy, Regulation and Governance, 19(1), 77-100.

Siau, K., \& Shen, Z. (2003). Mobile communications and mobile services Keng Siau and Zixing Shen. International Journal Mobile Communication, 1, 3-14.

Smura, T., Kivi, A., \& Töyli, J. (2009). A framework for analysing the usage of mobile services. Info, 11(4), 53-67.

Srinuan, C., Srinuan, P., \& Bohlin, E. (2013). Telematics and Informatics An analysis of mobile Internet access in Thailand: Implications for bridging the digital divide. Telematics and Informatics, 29(3), 254-262.

Tiwana, A., Konsynski, B., \& Bush, A. A. (2010). Platform evolution: Coevolution of platform architecture, governance, and environmental dynamics. Information Systems Research, 21(4), 675-687.

Varshney, U. (2005). Performance evaluation of protocols for group-oriented mobile services. Mobile Networks and Applications, 10(4), 465-474.

Wang, J., Lai, J. Y., \& Chang, C. H. (2016). Modeling and analysis for mobile application services: The perspective of mobile network operators. Technological Forecasting and Social Change, 111, 146-163.

Wang, K., \& Lin, C. L. (2012). The adoption of mobile value-added services: Investigating the influence of IS quality and perceived playfulness. Managing Service Quality, 22(2), 184-208.

Yen, D. C., Wu, C., Cheng, F., \& Huang, Y. (2010a). Computers in human behavior determinants of users' intention to adopt wireless technology: An empirical study by integrating TTF with TAM. Computers in Human Behavior, 26(5), 906-915.

Yen, D. C., Wu, C. S., Cheng, F. F., \& Huang, Y. W. (2010b). Determinants of users' intention to adopt wireless technology: An empirical study by integrating TTF with TAM. Computers in Human Behavior, 26(5), 906-915.

Yoo, Y., Henfridsson, O., \& Lyytinen, K. (2010). The new organizing logic of digital innovation: An agenda for information systems research. Information Systems Research, 21(4), 724-735.

Zammuto, R. F., Griffith, T. L., Majchrzak, A., Dougherty, D. J., \& Faraj, S. (2007). Information technology and the changing fabric of organization. Organization Science, 18(5), 749-762.

Zhou, T. (2014). Understanding continuance usage intention of mobile internet sites. 329-337.

Zhou, T., Lu, Y., \& Wang, B. (2010). Computers in human behavior integrating TTF and UTAUT to explain mobile banking user adoption. Computers in Human Behavior, 26(4), 760-767.

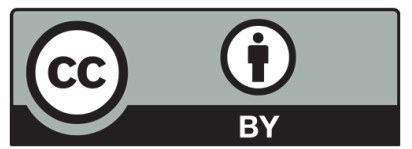

(C) 2020 by the authors; licensee Growing Science, Canada. This is an open access article distributed under the terms and conditions of the Creative Commons Attribution (CC-BY) license (http://creativecommons.org/licenses/by/4.0/). 